\title{
Adicción o abuso del teléfono móvil. Revisión de la literatura.
}

\section{Mobile phone abuse or addiction. A review of the literature.}

\author{
Eduardo J. Pedrero Pérez ; María Teresa Rodríguez

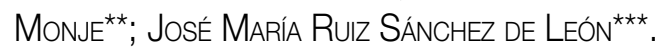

\author{
${ }^{*}$ Centro de Atención a Drogodependientes San Blas (CAD 4); Instituto de \\ Adicciones; Ayuntamiento de Madrid. \\ ${ }^{* *}$ CS M ${ }^{a}$ Ángeles López Gómez. Gerencia de Atención Primaria de Madrid. \\ ${ }^{\star \star \star}$ Dpto. Psicología Básica II (Procesos Cognitivos); Universidad Complutense \\ de Madrid.
}

\author{
Enviar correspondencia a: \\ Eduardo J. Pedrero Pérez \\ CAD 4 San Blas. Instituto de Adicciones. Madrid Salud. \\ Ayuntamiento de Madrid. \\ C/ Alcalá, 527 \\ 28027 - Madrid \\ E-mail: ejpedrero@yahoo.es \\ Teléfono: 917434771 - Fax: 917434775
}

recibido: Octubre 2011 aceptado: Marzo 2012

\section{Resumen}

El teléfono móvil es un instrumento tecnológico relativamente nuevo, versátil y accesible, muy atractivo, especialmente para jóvenes, cuyo uso conlleva riesgo de abuso y comportamiento adictivo. En los últimos años ha aumentando el interés por este problema, especialmente por la implicación de población cada vez más joven. El objetivo del presente trabajo es revisar el estado actual del conocimiento sobre la adicción/ abuso del móvil. Para ello, se efectuó una búsqueda en bases de datos internacionales, utilizando los descriptores "mobile phone", "cellular telephones", "addiction" y "abuse", focalizándose en estudios de prevalencia, pruebas diagnósticas, asociaciones con variables psicológicas y diferencias de género. Se observa una indefinición conceptual sobre los conceptos de abuso y adicción al móvil, gran disparidad en la adopción de criterios diagnósticos y multiplicidad de instrumentos para su estimación. Consecuentemente, la prevalencia estimada oscila entre $0-38 \%$, en función de la escala y características de la población estudiada. La autoatribución de adicción al móvil supera la estimación que alcanzan los mismos estudios. El rasgo de personalidad más consistentemente asociado a adicción es la baja autoestima, aunque la extraversión se relaciona con uso más intenso. Las mujeres con baja autoestima representan el grupo más vulnerable. El síntoma psicopatológico más comúnmente asociado fue la depresión. En definitiva, se evidencia que existe una problemática relacionada con el uso del teléfono móvil, pero la ausencia de criterios diagnósticos y la precaria calidad de los estudios dificultan la definición del problema. Es necesario delimitar y unificar criterios que permitan realizar estudios comparables y de calidad.

Palabras clave: Teléfono móvil, adicciones comportamentales, revisión, nuevas tecnologías, diagnóstico.
The mobile phone is a relatively new technological tool, versatile and accessible, and very attractive, especially for young people, but whose use involves a risk of abuse and addictive behavior. In recent years there has been increasing interest in this problem, especially in view of the fact that it involves an increasingly younger population. The aim of this paper is to review the current state of scientific knowledge about cell phone addiction/abuse. To this end, a search was carried out in international databases, using the descriptors "mobile phone", "cellular telephones", "addiction" and "abuse", and focusing on prevalence studies, diagnostic tests, associations with psychological variables and gender differences. There is a conceptual vagueness about the concepts of abuse and addiction in relation to mobile phones, and wide disparity in the adoption of diagnostic criteria; moreover, there are numerous instruments for the assessment of these concepts. As a result, the estimated prevalence ranges from $0-38 \%$, depending on the scale used and the characteristics of the population studied. Surprisingly, self-attribution of cell phone addiction exceeds the prevalence estimated in the studies themselves. The personality trait most consistently associated with addiction is low self-esteem, though extraversion is associated with more intense use. Women with low self-esteem are the most vulnerable group, and the most commonly associated psychopathological symptom was depression. In short, while the evidence suggests a problem in relation to mobile phone use, the vagueness of the cell phone addiction concept and the poor quality of the studies make it difficult to generalize the results. It is necessary to define and unify criteria with a view to carrying out quality studies that permit appropriate comparisons.

Key words: Mobile phone, behavioral addictions, review, new technologies, gender differences, diagnosis. 
L a incorporación del teléfono móvil a la actividad cotidiana de los seres humanos ha supuesto uno de los acontecimientos con mayor impacto social en las dos últimas décadas, sólo comparable a la aparición de Internet (Ling, 2004). El teléfono móvil ha pasado de ser un mero instrumento de comunicación interpersonal a convertirse en una plataforma de creciente complejidad, que impacta en la esfera privada y se proyecta a la esfera pública en condiciones difícilmente comprensibles sólo unos años atrás (Buchinger, Kriglstein, Brandt y Hlavacs, 2011; Hartmann, Rössler y Höflich, 2008). Si en un principio cabía considerar al móvil como un teléfono inalámbrico privado, ahora ésa es sólo una de sus múltiples utilidades, debiendo considerarse en el momento actual como una plataforma que oferta servicios variados, especialmente dirigidos a los más jóvenes, que no ha acabado de incorporar aún todas las funcionalidades posibles (Buchinger et al., 2011).

Comunicación, juego, fotografía, participación en redes sociales, descarga y escucha de música, televisión, apuestas online, radio, noticias, descarga y visionado de películas y telefilmes, etc. Una multioferta de estas características, tan variada, atractiva e interesante no puede estar exenta de problemas. Como señala Griffiths (2008), cualquier actividad gratificante es potencialmente adictiva, pero sólo aquellas marcadas por la desaprobación social por sus riesgos asociados son consideradas "adicciones" y no meros hábitos. En el caso de los móviles, las razones que han llevado a su consideración adictiva se refieren principalmente a la eclosión en la esfera privada de niños y adolescentes, el tiempo y la atención empleados por estas poblaciones en el uso de los móviles, la sustitución de otras actividades y la pérdida de control.

En la actualidad las 'adicciones comportamentales' estarían incluidas en el epígrafe de Trastornos del Control de los Impulsos del DSM-IV TR (APA, 2000) y, de ellas, sólo el juego patológico es considerado categoria diagnóstica independiente, quedando el resto incluidas en el capítulo "Trastornos del control de los impulsos no especificados". En la prevista $5^{a}$ edición del DSM se ha propuesto la creación de la categoría "Uso de sustancias y trastornos adictivos" en la que finalmente parece que sólo se incluirá el juego patológico, pero no el resto de las propuestas 'adicciones sin sustancia', o comportamentales (APA, 2011).

En realidad, el móvil actualmente incorpora todo aquello que hasta no hace mucho se relacionaba con la adicción a Internet (Ishii, 2004), de modo que debe considerarse en el momento actual como una plataforma potencialmente multiadictiva en la medida en que ofrece una gama inagotable de fuentes de reforzamiento, que se traduce en una gran aceptación entre los más jóvenes (Walsh, White y Young, 2008).

Las adicciones comportamentales, y entre ellas la adicción al móvil, han centrado un interés creciente entre un buen número de investigadores, de modo que cada año se han ido incrementando los trabajos publicados sobre el tema. Un estudio bibliométrico (Carbonell, Guardiola, Beranuy y Bellés, 2009) exploró el número de publicaciones entre 1996 y 2005 , encontrando que el mayor número de estudios se correspondía con los años $2004(n=42)$ y 2005 ( $n=40)$, si bien entonces la adicción al teléfono móvil sólo representaba el 2,2\% $(n=4)$ del total de artículos encontrados. Sin embargo, una somera exploración de los buscadores más generales indica claramente que el teléfono móvil ha adquirido, en la segunda mitad de la misma década, un especial protagonismo, quizá por su capacidad para absorber y movilizar otros medios, como el propio Internet. Pero no sólo en la literatura científica se objetiva un aumento de interés por el riesgo de adicción al móvil: los medios de comunicación se hacen eco de un cierto grado de alarma social ante la observación de que muchos adolescentes, cada vez con menor edad, parecen incapaces de prescindir de su teléfono móvil dedicando muchas horas a utilizarlo, y lo que ello supone de riesgo de una posible adicción y de los perjuicios sobre el funcionamiento psicológico y social de los jóvenes, apelando, a menudo, a ciertos estudios que, con gran difusión mediática, avalan la dimensión psicopatológica del problema (ej., Merlo y Stone, 2007). A pesar de todo lo anterior, en ámbitos clínicos persisten muchas dudas sobre el carácter adictivo del uso del móvil, las consecuencias psicopatológicas asociadas, las intervenciones terapéuticas indicadas, etc.

Se ha asociado el uso del móvil, en función de las motivaciones subyacentes, a seis categorias de conducta: adictiva, compulsiva, habitual, dependiente, obligatoria (impuesta por los usos sociales) y voluntaria; así, los individuos pueden ser clasificados en una de estas seis categorias propuestas (Hooper y Zhou, 2007). Algunos autores sugieren la consideración de una adicción positiva, en la medida en que la implicación en el uso del móvil reduce la probabilidad de otros hábitos, como la conducta de fumar (Cassidy, 2006). Tampoco hay que olvidar que éstas actividades gratificantes no son las únicas que cabe atribuir al teléfono móvil, siendo también altamente valoradas por los usuarios la posibilidad de ser localizado físicamente y la intimidad en las comunicaciones (LaRue, Mitchell, Terhorst y Karimi, 2010), o la comunicación con los padres como medio de seguridad de los de menor edad (Davie, Panting y Charlton, 2004), entre otras.

El abuso o la adicción no son los únicos efectos nocivos que se han atribuido al uso de teléfonos móviles; se han investigado otros efectos perjudiciales relacionados con las distintas formas de acoso vía móvil (Turan, Polat, Karapirli, Uysal y Turan, 2011) y un aumento del riesgo de accidentes laborales y de tráfico, vinculados a la interferencia sensorial durante su uso (Backer-Grøndahl y Sagberg, 2011). Por otro lado, y dado que el teléfono móvil funciona mediante emisión y recepción de ondas electromagnéticas de baja frecuencia (radiofrecuencias), se han realizado estudios para investigar los posibles efectos neurológicos y neuropsicológicos que pudiera ocasionar su aplicación en la superficie craneal; asi como su posible relación con tumores intracraneales, en la medida en que algunas longitudes de onda del espectro electromagnético parecen tener efectos perjudiciales sobre la salud (Heinrich, Thomas, Heumann, von Kries y Radon, 2011).

El presente trabajo tiene como objetivo revisar, mediante una búsqueda bibliográfica, el estado actual de conocimiento científico sobre la adicción y/o el uso abusivo de los teléfonos móviles, para conocer el alcance del problema en térmi- 
nos de prevalencia y consecuencias relacionadas con dicho uso, así como la determinación de los posibles factores de riesgo, tales como variables psicológicas asociadas y la existencia de diferencias de género.

\section{Método}

Se consultaron las bases de datos Academic Search Premier, Business Source Complete, CINAHL, Pro-Quest, Communication \& Mass Media Complete, EconLit, ERIC, Library, Information Science \& Technology, MEDLINE, The Serials Directory y Psyclnfo. Se seleccionaron artículos publicados en revistas académicas con revisión por pares. Se utilizaron y combinaron como descriptores de búsqueda los siguientes términos: "mobile phone", "cellular telephone", "cell phone", "addiction", "behavior", "addictive" y "abuse"; como límites se utilizaron los años entre 2000 y 2011 y el idioma en inglés, español y francés; cuando fue posible se revisaron las "citas relacionadas" con las referencias obtenidas (ej: related citations en PubMed) hasta saturar la búsqueda; se realizó también una indagación secundaria a partir de los descriptores que utilizaban los trabajos encontrados. Finalmente, de esta primera búsqueda se obtuvieron 128 artículos.

A partir del resumen se retuvieron aquellos artículos que efectuaban algún tipo de estudio empírico: (a) aportaban instrumentos diagnósticos, (b) o para la detección de problemas asociados al uso o abuso del teléfono móvil, (c) establecian cifras de prevalencia, (d) buscaban asociaciones con variables de índole psicológica o (e) exploraban diferencias de género. De los 49 trabajos que se obtuvieron a texto completo, se seleccionaron 46 que ofrecian una metodología aceptable.

Posteriormente se revisaron las referencias bibliográficas de los artículos seleccionados, repitiendo el proceso hasta saturar la búsqueda; este proceso proporcionó 28 artículos válidos.

También se realizó una búsqueda oportunista en bases de la llamada literatura gris, incluyéndose los estudios que aportaran datos de interés para el presente trabajo, siempre que publicaran la metodología seguida y ésta fuera correcta y adecuada. Este procedimiento permitió incluir 12 trabajos más. Además de los estudios empíricos, se recuperaron estudios que formalizaban propuestas teóricas o metodológicas para el estudio científico del problema. Finalmente se seleccionaron 86 artículos.

\section{Resultados}

\section{Adicción al móvil: marco conceptual}

Existe constancia de que el uso inadecuado y sin control de la telefonía móvil puede causar problemas comportamentales, afectivos y sociales, y se caracteriza por los mismos elementos que el DSM-IV-TR enumera para la considera- ción de una conducta como trastorno adictivo: síntomas de abstinencia, falta de control, problemas derivados del uso y la tolerancia e interferencia con otras actividades (Chóliz, 2010). Los sintomas de la retirada o no disponibilidad (en este caso, del aparato de telefonía móvil) y el sentimiento de pérdida asociado, que se acompañan de manifestaciones como ansiedad, la excesiva relevancia ('salience') del uso del móvil en el repertorio conductual y la interferencia con otras actividades de la vida diaria son considerados los indicadores más claros de adicción, que pueden llevar a una pérdida de control y a la experimentación de un patrón de obsesión/ compulsión en el uso. Otros autores, sin embargo, consideran inadecuado hablar de adicción al móvil, estimando más adecuado el término "abuso", en la medida en que no conduce a cambios emocionales rápidos y alternancia de falsas identidades, como sucede cuando el medio utilizado es Internet (Sanchez-Carbonell, Beranuy, Castellana, Chamarro y Oberst, 2008). Otra cuestión no resuelta a día de hoy es si cabe hablar de adicción a la plataforma o a los contenidos que en ella se ofrecen. Por ejemplo, puede estudiarse como una entidad independiente la adicción al envío de mensajes breves de texto ('sms'), dado que presenta características específicas como conducta y se asocia a personalidades y manifestaciones psicopatológicas también específicas (Lu, Watanabe, Liu, Uji, Shono y Kitamura, 2011). La consecuencia de esta indefinición conceptual es que cada uno de los trabajos disponibles recurre a unos $u$ otros criterios para estudiar el fenómeno del uso excesivo de teléfonos móviles.

\section{Instrumentos diagnósticos}

Se han elaborado múltiples instrumentos para el estudio del uso disfuncional del teléfono móvil; ello da idea de la variedad e imprecisión de los criterios utilizados. Generalmente se basan en los criterios DSM-IV de juego patológico y/o de adicción. En la Tabla 1 se resumen las características principales de los utilizados en los estudios seleccionados en esta revisión.

Entre ellos, cabe destacar la escala MPPUS (Mobile Phone Problem Use Scale), desarrollada por Bianchi y Phillips (2005), que ha sido el instrumento más ampliamente usado, y que podría considerarse como el 'patrón oro' para el estudio de esta problemática. La escala ha mostrado una moderada correlación con otras medidas de uso del móvil, como el tiempo informado de uso durante una semana $(r=0,45)$, el número de personas llamadas $(r=0,42)$ o el gasto mensual $(r$ $=0,43)$. También mostró correlación $(r=0,34)$ con una escala que mide el potencial individual para desarrollar una adicción (Addiction Potential Scale, APS) extraída del MMPI-2.

A partir de la escala MPPUS, Leung (2007) seleccionó y modificó 17 ítems que concordaban con los criterios DSM-IV para juego patológico (que habian sido utilizados previamente para medir la adicción a Internet).

En España, el Cuestionario de Experiencias Relacionadas con el Móvil (CERM; Beranuy Fargues, Chamarro Lusar, Graner Jordania. y Carbonell Sánchez, 2009) se basa en otro diseñado para estudio de la adicción a Internet: el cuestionario 
Tabla 1. Comparativa de escalas para el estudio de la adiccion al móvil.

\begin{tabular}{|c|c|c|c|c|}
\hline Instrumento (abreviatura) & Autor / año publicacion & Ítems: $\mathrm{n}^{\circ}$ y tipo & $\alpha$ de Crombach & Crierios de base \\
\hline $\begin{array}{l}\text { Mobile Phone Dependence Questionnaire } \\
\text { (MPDQ) }\end{array}$ & Toda et al. 2004 & 20 Likert & $\alpha=0,86$ & Observación de la conducta de los usuarios del movil \\
\hline Mobile Phone Problem Use Scale (MPPUS) & Bianchi y Phillips 2005 & 27 Likert & $\alpha>0,90$ & $\begin{array}{l}\text { Explora: tolerancia, huida de los problemas, absti- } \\
\text { nencia, deseo compulsivo y consecuencias negativas } \\
\text { familiares, laborales y económicas }\end{array}$ \\
\hline $\begin{array}{c}\text { Self-perception of Text-message Dependency } \\
\text { Scale (STDS) }\end{array}$ & Halayem 2005 & 15 Likert & No pruebas de validación & $\begin{array}{l}\text { Adicción a los mensajes breves de texto. Sin marco } \\
\text { teórico de referencia explicito. }\end{array}$ \\
\hline Mobile Phone Addiction Index (MPAI) & Leung 2007 & 17 Likert & $\alpha>0,90$ & $\begin{array}{l}\text { Criterios DSM-IV para juego patológico y criterios de } \\
\text { Young (1996) para adicción a Internet. }\end{array}$ \\
\hline Cell-Phone Over-Use Scale (COS) & Jenaro et al. 2007 & 23 Likert & $\alpha=0,87$ & $\begin{array}{l}\text { Criterios DSM-IV para la clasificación del juego } \\
\text { patológico }\end{array}$ \\
\hline Excessive Cellular Phone Use Survey (ECPUS) & Ha et al. 2008 & 20 Likert & No pruebas de validación & Experiencia clinica de los autores \\
\hline $\begin{array}{l}\text { Problematic Mobile Phone Use Questionnaire } \\
\text { (PMPUQ) }\end{array}$ & Billieux et al. 2008 & $\begin{array}{l}30 \text { Likert }+1 \\
\text { dicotómico }\end{array}$ & $\begin{array}{c}0,65<\alpha<0,85 \text { para las } 4 \\
\text { dimensiones }\end{array}$ & $\begin{array}{l}\text { Estudia cuatro dimensiones: uso peligroso, uso } \\
\text { prohibido, problemas económicos y sintomas de } \\
\text { dependencia. Sin marco teórico de referencia explícito. }\end{array}$ \\
\hline $\begin{array}{l}\text { Escala de Medición del Uso Problemático } \\
\text { del Móvil }\end{array}$ & $\begin{array}{l}\text { Instituto de Adicciones Madrid } \\
2008\end{array}$ & 9 Likert & $\alpha=0,80$ & $\begin{array}{l}\text { Estudia el uso problemático de tecnologías. Sin marco } \\
\text { teórico de referencia explicito. }\end{array}$ \\
\hline Test of Mobile Phone Dependence & Chóliz y Villanueva 2009, 2011 & 38 Likert & $\begin{array}{c}\text { Escalas } \\
0,85<\alpha<0,91\end{array}$ & $\begin{array}{l}\text { Criterios DSM-IV-TR para dependencia (tres factores: } \\
\text { abstinencia, pérdida de control/problemas derivados y } \\
\text { tolerancia/interferencia con otras actividades) }\end{array}$ \\
\hline $\begin{array}{l}\text { Cuestionario de Experiencias Relacionadas } \\
\text { con el Móvil (CERM) }\end{array}$ & Beranuy Fargues el al. 2009 & 10 Likert & $\alpha=0,80$ & $\begin{array}{l}\text { Criterios DSM-IV, tanto de adicción, como de } \\
\text { juego patológico (dos factores: conflictos y uso } \\
\text { comunicacional/emocional) }\end{array}$ \\
\hline $\begin{array}{l}\text { Cell Phone Addiction Scale for Korean } \\
\text { Adolescents (CPAS) }\end{array}$ & Koo 2009 & 25 Likert & No pruebas de validación & Experiencia clinica de los autores \\
\hline $\begin{array}{l}\text { Cuestionario de Detección de Nuevas } \\
\text { Adicciones (DENA) }\end{array}$ & Labrador y Villadangos 2010 & $\begin{array}{l}12 \text { items: } 4 \text { tiempo y } \\
\text { gasto; } 8 \text { uso y abuso }\end{array}$ & No pruebas de validación & Criterios DSM-IV-para juego patológico \\
\hline $\begin{array}{l}\text { Mobile Phone Involvement Questionnaire } \\
\text { (MPI0) }\end{array}$ & Walsh et al. 2010 & 8 Likert & $\alpha=0,80$ & $\begin{array}{c}\text { Concepto de adicción comportamental de } \\
\text { Brown (1997); explora la vinculación cognitiva y } \\
\text { comportamental con el movil }\end{array}$ \\
\hline $\begin{array}{l}\text { Text Messaging Gratification Scale } \\
\text { (TMG) }\end{array}$ & Grellhesl 2010 & 47 Likert & 0,86 & $\begin{array}{l}\text { Adicción a los mensajes breves de texto. Sin marco } \\
\text { teórico de referencia explícito. }\end{array}$ \\
\hline Mobile Addiction Test (MAT) & Martinotti et al. 2011 & 10 Likert & No pruebas de validación & $\begin{array}{l}\text { Uso problemático del móvil. Sin marco teórico de } \\
\text { referencia explicito. }\end{array}$ \\
\hline
\end{tabular}

Problemas Relacionados con el Uso de Internet (PRI; de Gracia Blanco, Vigo Anglada, Fernández Pérez y Marcó Arbonès, 2002), que tenía en cuenta los criterios DSM-IV, tanto de adicción, como de juego patológico.

Otros autores han utilizado cuestionarios de diversas procedencias o elaborados ad hoc, sin informar de sus propiedades psicométricas (Butt y Phillips, 2008; Chen, 2006; Hooper y Zhou, 2007; Kamibeppu y Sugiura, 2005; Perry y Lee, 2007; Rutland, Sheets y Young, 2007; Sánchez-Martínez y Otero, 2009; Söderqvist, Hardell, Carlberg y Hansson, 2007; Thomée, Härenstam y Hagberg, 2011; Viñas y González, 2010; Walsh, White y Young, 2007).

\section{Prevalencia de la adicción al móvil}

En la Tabla 2 se resumen los resultados de los trabajos que aportan datos de prevalencia en las muestras estudiadas. Como puede observarse, ésta oscila entre el 0 y el $38 \%$. Sin embargo, hay que hacer constar que el concepto de 'adicción' se superpone, en los diferentes estudios con el de 'dependencia', 'abuso', 'usuarios duros' ('hard users') y otros, de modo que se ha respetado la denominación que cada trabajo efectúa de los consumidores considerados problemáticos. También hay que hacer constar que en los trabajos reseñados apenas existe coincidencia en los instrumentos utilizados para el estudio, lo que imposibilita la comparabilidad de los resultados. Las muestras utilizadas corresponden, casi en su totalidad, a poblaciones de adolescentes y jóvenes, disponiéndose de un solo trabajo que estudie el problema en personas mayores de 32 años. Un estudio compara los patrones de uso de jóvenes universitarios y profesionales, no encontrando diferencias ni comportamientos que sugieran diferencias en comportamiento adictivo (Ahmed, Ramzan, Qazi y Jabeen, 2011). Las muestras utilizadas suelen ser de conveniencia, siendo el método más habitual la distribución de una encuesta que es cumplimentada voluntariamente, con una tasa de respuesta que oscila entre el 69\% (Lu et al., 2011) y el $98,5 \%$ (Toda, Monden, Kubo y Morimoto, 2006). Sin embargo, también existen trabajos con determinados niveles de aleatorización en la búsqueda de teléfonos a los que Ilamar para solicitar participación (Leung, 2007), o entrevistando a las 25 primeras personas que aparecen (Perry y Lee, 2007) o técnicas más sofisticadas, como el muestreo en múltiples etapas (Zulkefly y Baharudin, 2009). 
Tabla 2. Prevalencia de adicción/dependencia al/del móvil según los estudios encontrados.

\begin{tabular}{|c|c|c|c|c|c|c|}
\hline Autores & Lugar & Instrumento & $\mathrm{N}$ & Edades & Varones/mujeres & Prevalencia \\
\hline PROTÉGELES, 2005 & España & Ad hoc & $\begin{array}{c}2.000 \\
(1 \mathrm{a})\end{array}$ & $11-17$ & n.c. & 38\% declaró sintomas de dependencia del móvil. \\
\hline Instituto de Adicciones, 2008 & Madrid & Ad hoc & $\begin{array}{l}556 \\
(0 b .)\end{array}$ & $12-25$ & n.c. & $\begin{array}{l}\text { 8,5\% de los jóvenes plantea alguna problemática con el } \\
\text { uso de los móviles y 0,4\% reconocen problemas tanto de } \\
\text { necesidad, como preocupación o uso compulsivo. }\end{array}$ \\
\hline Toda et al., 2006 & Japón & MPDO & $\begin{array}{l}271 \\
(2 c)\end{array}$ & $\begin{array}{l}21.5 \pm 1.8 \text { (varones) } \\
21.3 \pm 1.4 \text { (mujeres) }\end{array}$ & $43,2 \%-56,8 \%$ & $\begin{array}{l}18.8 \% \text { de varones y } 17.5 \% \text { de mujeres obtuvieron } \\
\text { puntuaciones que sugerian dependencia del móvil. }\end{array}$ \\
\hline Beranuy Fargues et al., 2006 & Barcelona & CERM & $\begin{array}{l}430+209 \\
(1 c d)\end{array}$ & $\begin{array}{l}13-18 \\
19-25\end{array}$ & $\begin{array}{c}49,5 \% / 50,5 \% \\
18 \% / 82 \%\end{array}$ & $\begin{array}{l}5,35 \% \text { de adolescentes y 5,26\% de jóvenes podia } \\
\text { considerarse adicto al móvil. }\end{array}$ \\
\hline Leung, 2007 & Amsterdam & MPAI & $\begin{array}{l}624 \\
(3 e)\end{array}$ & $14-28$ & $51.8 \% / 62.1 \%$ & $\begin{array}{l}28,7 \% \text { de la muestra podia clasificarse como adicta al } \\
\text { teléfono móvil }\end{array}$ \\
\hline Perry et al., 2007 & Mauricio & Ad hoc & $\begin{array}{l}214 \\
(3 c)\end{array}$ & $19-25$ & $46 \%-54 \%$ & Entre el $6 \%$ y el $11 \%$ mostraron signos de adicción. \\
\hline Jenaro at al., 2007 & Salamanca & $\cos$ & $\begin{array}{l}337 \\
(2 c)\end{array}$ & $18-32$ & $24 \% / 74.8 \%$ & $\begin{array}{l}10,4 \% \text { de los participantes podia considerarse adicto al } \\
\text { móvil. }\end{array}$ \\
\hline Leung, 2008 & Hong Kong & MPA & $\begin{array}{l}402 \\
(3 e)\end{array}$ & $14-20$ & $46 \%-54 \%$ & $27,4 \%$ pueden ser considerados adictos al móvil. \\
\hline Koo, 2009 & Korea & CPAS & $\begin{array}{l}577 \\
(1 d)\end{array}$ & Adolescentes & $49.9 \% / 50.1 \%$ & $\begin{array}{l}2,9 \% \text { son clasificados como adictos y el 8,2\% como } \\
\text { usuarios problemáticos. }\end{array}$ \\
\hline Sánchez-Martinez et al., 2009 & Madrid & $\begin{array}{c}\text { Ad hoc } \\
\text { (2 preguntas) }\end{array}$ & $\begin{array}{l}1328 \\
(1 d)\end{array}$ & $13-20$ & $46,3 \% / 53,7 \%$ & $\begin{array}{l}20 \% \text { cumplian criterios de dependencia del móvil, } 26,1 \% \text { de } \\
\text { las mujeres y } 13 \% \text { de los varones }\end{array}$ \\
\hline Zulkefly et al., 2009 & Singapur & MPS & $\begin{array}{l}386 \\
(3 d)\end{array}$ & $18-32$ & $54,1 \%-45,9 \%$ & Ningún participante mostró adicción al móvil. \\
\hline Koo, 2010 & Korea & CPAS & $\begin{array}{l}469 \\
(1 d)\end{array}$ & $\begin{array}{l}\text { Estudiantes de } \\
\text { secundaria }\end{array}$ & $33 \%-67 \%$ & $\begin{array}{l}4,1 \% \text { cumplian criterios de adicción y el 7,5\% eran usuarios } \\
\text { abusivos del móvil. }\end{array}$ \\
\hline Halayem et al., 2010 & Túnez & STDS & $\begin{array}{l}120 \\
(1 d)\end{array}$ & $13-20$ & $32,5 \%-67,5 \%$ & $33,4 \%$ presentaban signos de dependencia del móvil. \\
\hline Lu et al., 2011 & Japón & STDS & $\begin{array}{l}146 \\
(2 f)\end{array}$ & $22-59$ & $63 \%-37 \%$ & $\begin{array}{l}3,1 \% \text { de varones y } 5,4 \% \text { de muejres mostraron dependencia } \\
\text { leve de los mensajes de texto del móvil. Ningún caso de } \\
\text { dependencia grave. }\end{array}$ \\
\hline Martinotti et al., 2011 & Italia & MAT & $\begin{array}{l}2853 \\
(1 d)\end{array}$ & $13-20$ & $59,6 \%-40,4 \%$ & $\begin{array}{l}6,15 \text { de varones y } 6,5 \% \text { de mujeres mostraron uso } \\
\text { problemático del móvil. }\end{array}$ \\
\hline
\end{tabular}

Nota: En la columna N se hace Constar el método de obtención de la muestra: 1 . Muestreo de conveniencia; 2 . Respuesta espontánea a encuestas; 3 . Muestreo probabilistico; 0 . no consta procedimiento de muestreo. Lugar de realización: a. En la calle; b. En el hogar; c. En la universidad; d. En escuelas/colegios; e. Por teléfono; f. En el trabajo.

\section{Autoatribución de adicción al móvil}

Igarashi, Motoyoshi, Takai y Yoshida (2004) estudiaron los componentes de la autoatribución de adicción al móvil, encontrando tres: percepción de uso excesivo, reacciones emocionales (ej., frustración al no recibir respuesta inmediata a los mensajes de texto) y motivación para el mantenimiento de las relaciones. Un estudio suizo (Billieux et al., 2008) exploró qué factores predicen la autoatribución de 'adicto al móvil', encontrando algunas subdimensiones de la impulsividad, como impaciencia y baja perseverancia, combinados con un largo tiempo de posesión del móvil.

En un estudio realizado en Barcelona con 430 adolescentes escolarizados en colegios públicos y 209 jóvenes universitarios (Beranuy Fargues, Sánchez Carbonell, Graner Jordania, Castellana Rosell y Chamarro Lusar, 2006), un 22,1\% de los adolescentes y un $27,9 \%$ de los jóvenes se consideraron a sí mismos como 'adictos al móvil'. De entre los que componían el grupo de alto riesgo, el 79,4\% se autoconsideraron adictos al móvil. Sin embargo, del total de quienes se con- sideraron adictos al móvil sólo un 5,3\% de ellos estarían en este grupo extremo. Un 15,8\% de los entrevistados en el estudio realizado en la República de Mauricio (Perry y Lee, 2007) admitieron ser adictos al móvil. Un estudio sobre 120 adolescentes entre 13 y 20 años en Túnez (Halayem et al., 2010) encontró que el $31,7 \%$ consideraban de sí mismos que realizaban un uso excesivo del móvil, principalmente para el envío de mensajes de texto y la realización de 'llamadas perdidas'. Un trabajo realizado en los Emiratos Árabes (Hashem, 2009) encontraba que el $67 \%$ de los varones y el $75 \%$ de las mujeres se tenían a sí mismos por adictos al móvil, debido, principalmente, a su uso diario de entre 4 y 7 horas. Por el contrario, en el estudio de Chen (2006) ninguno de los 166 participantes declaró sentirse adicto al móvil.

\section{Relación con variables psicológicas}

Uno de los rasgos más estudiados en relación al abuso del móvil ha sido la autoestima, bajo la hipótesis de que las personas con baja autoestima pueden utilizar el móvil para evi- 
tar los contactos cara a cara y expresarse con más facilidad en la comunicación mediada. Por otra parte, la baja autoestima es un hallazgo habitual en los estudios de adictos a sustancias, por lo que la consideración del abuso del móvil como adicción debería acompañarse de correlatos psicopatológicos similares. Bianchi y Phillips (2005) compararon los resultados obtenidos mediante el MPPUS con los que resultaron de la cumplimentación del Cuestionario de Autoestima de Coopersmith en una muestra de 195 sujetos mayores de 18 años, reclutados directamente en campus universitarios, vías públicas 0 a través de anuncios en locales públicos. Encontraron que la baja autoestima se relacionó con el uso problemático del móvil, pero no con variables del uso normal; los autores hacen constar que no es posible establecer una línea de causalidad, en la medida en que un uso inapropiado puede generar consecuencias negativas que impacten en la autoestima, del mismo modo que una baja autoestima puede llevar a un uso inapropiado del móvil. Ha et al. (2008), sobre una muestra de 1200 estudiantes coreanos, con una media de 16 años, utilizando el ECPUS, encontraron también menores niveles de autoestima (mediante la Rosenberg Self-Esteem Scale) en quienes podían ser clasificados como abusadores del móvil. Ehrenberg, Juckes, White y Walsh (2008) obtuvieron resultados similares utilizando la Self-Esteem Inventory Adult Form en una muestra de 200 universitarios australianos, resultando ser la baja autoestima uno de los más potentes predictores de tendencias adictivas en el uso de móviles. Zulkefly y Baharudin (2009), en un estudio con 386 universitarios de Malasia, utilizando la Rosenberg Self-Esteem Scale, encontraron que era más probable que los estudiantes con baja autoestima desarrollaran un patrón adictivo con el móvil. En el estudio de Leung (2007), en cambio, la autoestima, medida también por la escala de Rosenberg, no mostró relación significativa con el uso del móvil, ni mostró diferencias entre adictos y no adictos, en una muestra de 624 adolescentes chinos. Butt y Phillips (2008) tampoco encontraron tal relación en un estudio con 115 trabajadores australianos de edades entre 18 y 59 años.

Se ha estudiado también la relación entre los rasgos propuestos por las principales teorías de la personalidad y el abuso del móvil. Bianchi y Phillips (2005) utilizaron el EPO de Eysenck. Como predijeron, la extraversión explicó variables de uso, como el tiempo consumido usando el móvil durante la semana, el número de llamadas y el uso problemático; sin embargo, no se relacionó con un uso social, en la medida en que los usuarios no buscaban con ello intensificar sus relaciones, sino más bien buscar estimulación. Contra lo previsto, el neuroticismo no se relacionó con el uso, ni normal ni problemático, del móvil. Ehrenberg et al. (2008) exploraron la relación entre los Cinco Grandes Factores de Personalidad (mediante el NEO-FFI) con diversas variables relativas al uso del móvil (número de llamadas, de 'sms', de mensajes instantáneos y tendencias adictivas). Encontraron que la baja afabilidad era el más potente predictor de tendencias adictivas en la utilización de mensajería instantánea y en el uso del móvil en general, mientras que el neuroticismo era un moderado predictor de adicción al móvil. La extraversión predecía el uso frecuente de 'sms' pero no las tendencias adictivas relacionadas con ese medio de comunicación. En un estudio coincidente en el tiempo y muy similar al interior, Butt y Phillips (2008) encontraron también que eran las dimensiones de afabilidad (baja) y extraversión (alta), pero no el neuroticismo, las que predecian la intensidad de uso del móvil. La baja afabilidad también predijo el grado de utilización de juegos en el móvil (Phillips, Butt y Blaszczynski, 2006).

Billieux et al. (2008) estudiaron una muestra de 430 voluntarios con edades comprendidas entre los 20-35 años, relacionando el uso del móvil con impulsividad. Utilizaron la escala UPPS (Van der Linden et al., 2006) que mide 4 subdimensiones de impulsividad (impaciencia, irreflexividad, inconstancia y búsqueda de sensaciones) y el PMPUQ. Utilizaron también el BDI y el STAI para controlar la sintomatología ansiosa y depresiva. Encontraron que el número de llamadas diaria mostraba correlación con las subdimensiones de impaciencia e irreflexividad; la duración de las llamadas lo hacía con impaciencia, irreflexividad e inconstancia; y el número de mensajes de texto, con impaciencia. Apareció también una correlación significativa entre la sintomatología ansiosa y depresiva y el número de mensajes cortos enviados diariamente. Únicamente la impaciencia mostró capacidad predictiva sobre los síntomas de dependencia del móvil.

En el ya citado estudio de Leung (2007), las personas que podian ser consideradas adictas al móvil mostraban puntuaciones elevadas en aburrimiento en el ocio ('leisure boredom') y búsqueda de sensaciones, además de hacer un uso general más intensivo (más minutos al día y llamadas de más duración, más mensajes enviados y recibidos, más grabaciones de audio y vídeo, más lectura de noticias, más descarga de politonos e imágenes, mayor proximidad del móvil durante las horas de sueño) que los sujetos que no podian considerarse adictos. En concreto, dedicaban el doble de tiempo diariamente al móvil que los no adictos $(108,82$ minutos frente a 54,41 minutos). Un estudio posterior del mismo autor (Leung, 2008), realizado sobre una muestra de adolescentes entre 14 y 20 años, encontraba que aquellos que combinaban altos niveles de aburrimiento en el ocio y búsqueda de novedad, con bajos niveles de autoestima, eran los que con mayor probabilidad podian desarrollar adicción al móvil.

Otro grupo de estudios abordó las relaciones entre abuso del móvil y variables de socialización. Un estudio llevado a cabo entre jóvenes rumanos (Prezza, Pacilli y Dinelli, 2004) no encontró relación alguna entre uso de móvil y sentimientos de soledad y aislamiento, a diferencia de lo que ocurrió con el uso de Internet. Chen (2007) estudió una muestra de 514 sujetos universitarios, combinando metodología cualitativa y cuantitativa. Encontró que, contrariamente a lo esperado -atendiendo a estudios previos-, lejos de favorecer el aislamiento social y comprometer la independencia personal, el uso del móvil debía considerarse un instrumento o un medio que favorecía la socialización, tanto en el ambiente académico como en el propio núcleo familiar. Tanto los padres como los jóvenes valoraron el teléfono móvil como medio para mantener la relación entre padres e hijos desde la distancia. Para la mayoría de los participantes en este estudio, el teléfono móvil resultaba "imprescindible" para mantener un contacto frecuente con su familia, para cum- 
plir con sus roles familiares, para compartir experiencias y recibir apoyo emocional y físico de sus padres. El móvil, pues, aparecía como instrumento útil para construir las habilidades personales de socialización sin requerir la ruptura de vínculos previos. En un estudio previo, Chen (2006) ya habia encontrado que el móvil favorece el incremento del "capital social", en la medida en que permite aumentar y mantener el núcleo de amistades y mejorar las relaciones familiares. Sin embargo, ese mantenimiento de las redes sociales requiere una inversión -de dinero y de tiempo-que aproxima el patrón de uso del móvil a lo que podría considerarse adicción. Una de las consecuencias es la percepción de que el uso del móvil interfiere con las tareas académicas y disminuye el rendimiento.

En Estados Unidos, sobre una muestra de 1450 estudiantes, Lee y Perry (2004) encontraron que los efectos de una deficiente autorregulación en el uso del móvil, especificamente en el uso de mensajes instantáneos, interfería significativamente con los procesos normales de socialización así como en actividades de la vida diaria, como disminución de las horas de sueño. Un estudio con 400 jóvenes coreanos encontró relación entre la adicción al móvil y características personales, como la imitación de pares, el bajo autocontrol y la ansiedad social. Sin embargo, no eran las conversaciones de voz las que predecian la conducta adictiva, sino el excesivo número de mensajes de texto (Park, Hwang y Huh, 2010).

Otro rasgo que apareció fuertemente asociado al uso problemático del móvil fue la "motivación para la aprobación" (Caplan, 2007; Chak y Leung, 2004), fuertemente asociado, a su vez, con baja autoestima, y en este caso, especialmente vinculado al tiempo dedicado a escribir y leer mensajes. Contra las predicciones de los autores, los sentimientos de soledad no predijeron un uso excesivo o problemático del móvil, ni en lo relativo al tiempo de uso durante la semana, ni el número de llamadas efectuadas, ni el tiempo dedicado a escribir y leer mensajes, ni el número de personas con las que se intercambiaron mensajes. En este sentido, el abuso del móvil parece diferenciarse claramente del abuso de Internet, siendo éste más probable en personas solitarias e introvertidas. En la misma línea, Takao, Takahashi y Kitamura (2009) estudiaron la relación de ciertos rasgos de personalidad y determinados usos del teléfono móvil. Para ello utilizaron una amplia muestra de estudiantes universitarios ( $n=444)$. Encontraron que el uso problemático del móvil era más probable en personas caracterizadas por una elevada tendencia a la "auto-monitorización comportamental" (tendencia a explorar señales externas de aprobación como guía de la propia conducta y susceptibilidad a la presión de grupo). Este rasgo ya había aparecido previamente asociado a conductas adictivas con sustancias (Sharp y Getz, 1996).

Se ha estudiado también la relación entre abuso del móvil y variables de salud. En cuanto a las variables psicopatológicas, Zulkefly y Baharudin (2009) encontraron que mucho tiempo con el móvil se relacionaba con la experimentación de trastornos psicopatológicos. El estudio de $\mathrm{Ha}$ et al. (2008) clasificó a los sujetos en tres grupos según su nivel de uso declarado. El grupo con mayor nivel de uso declaró mayor cantidad de sintomas depresivos (mediante el Cuestionario de Depresión de Beck), más dificultades en expresar sus emociones (mediante la Toronto Alexithymia Scale, TAS-20), mayores niveles de ansiedad interpersonal (mediante la Interaction Anxiousness Scale) y menores niveles de autoestima (mediante la Rosenberg Self-Esteem Scale); además mostraron puntuaciones más elevadas en la escala de Young para adicción a Internet (Young's Internet Addiction Scale). Thomée, Eklöf, Gustafsson, Nilsson y Hagberg (2007) efectuaron un estudio longitudinal prospectivo para estudiar las relaciones entre uso de nuevas tecnologías (entre ellas, el móvil) y resultados de salud. La suma de horas de ordenador y móvil durante la semana se asoció, al inicio del estudio, con un aumento del riesgo de estrés prolongado y síntomas de depresión al año de seguimiento. Además, el número de mensajes 'sms' enviados/recibidos por día se asoció con el padecimiento de estrés prolongado. Al analizar por separado a hombres y mujeres, los resultados mencionados fueron estadísticamente significativos sólo para las mujeres, pero la tendencia era similar para los varones, quienes, además, presentaban una asociación entre el alto número de llamadas de teléfono móvil y mensajes SMS con dificultades para conciliar el sueño. Estos resultados fueron confirmados por un estudio posterior del mismo grupo de investigación (Thomée et al., 2011).

En el estudio de Jenaro et al. (2007), y contra lo hipotetizado por los autores, no apareció relación significativa entre el uso abusivo del móvil y abuso o dependencia de sustancias, ni tampoco entre patrones de hábitos de vida saludables (ej. sueño y alimentación) y abuso del móvil. Por el contrario, encontraron que el abuso del móvil se relacionaba con mayor probabilidad de experimentar trastornos psicopatológicos, como insomnio, disfunciones sociales, depresión y ansiedad. Estos hallazgos concordaban con lo encontrado en muestras de menor edad en otros paises (Kamibeppu y Sugiura, 2005). Un estudio realizado en Madrid (Sánchez-Martínez y Otero, 2009) sobre una muestra de 1328 adolescentes (entre 13 y 20 años) escolarizados en enseñanza secundaria, encontró relaciones significativas entre uso intensivo del móvil y variables como pertenecer a la clase media, estudiar en centros públicos, pertenecer a un ámbito rural, tener fracaso escolar, presentar sintomas depresivos, ser fumadores de tabaco y consumidores de cannabis y otras drogas, tener mala relación familiar y tener padres con elevado nivel formativo, sin problemas económicos y una mala relación de pareja. Beranuy, Oberst, Carbonell y Chamarro (2009) encontraron, en una muestra de estudiantes universitarios, que el malestar psicológico, estimado mediante el inventario de síntomas SCL-90-R, se relacionó con un uso maladaptativo del móvil. Lu et al. (2011) encontraron correlación positiva entre la dependencia de los mensajes de texto y la depresión, y una correlación negativa con la ansiedad. Toda et al. (2006) no encontraron relación entre uso y abuso del móvil y variables de hábitos de vida, salvo una correlación significativa entre el abuso del móvil y el hábito de fumar en varones. Augner y Hacker (2011) han encontrado relación entre abuso del móvil y estrés crónico, baja estabilidad emocional y depresión, especialmente en mujeres y en personas de baja edad.

Se ha explorado qué condiciones predicen con mayor significación el uso problemático del móvil. Labrador y Villa- 
dangos (2010) estudiaron las conductas que podrian operar como indicadores de adicción al móvil, encontrando que hay ciertas conductas asociadas al uso de nuevas tecnologías que, dada su similitud con los sintomas de adicciones ya establecidas, parecen indicar que el uso de dichas nuevas tecnologías puede generar adicción. Resalta el valor elevado, en el caso del móvil, de la conducta "consultas frecuentes", consistente en mirar con insistencia la pantalla para ver si hubo alguna Ilamada o SMS. Este tipo de conducta, aunque no guarda mucha similitud con los síntomas de las adicciones, puede ser un índice del nivel de dependencia del móvil. Un estudio realizado sobre una muestra de 469 estudiantes coreanos de secundaria (Koo, 2010), encontró que los principales predictores de abuso del móvil fueron: autocontrol percibido, uso de los mensajes de texto, minutos diarios dedicados a llamadas, escuchar música en el móvil, ser mujer, gasto mensual, depresión, número de amigos contactados y autoeficacia percibida. En su conjunto, estas variables explicaban el 39\% de la varianza en la adicción al móvil. Walsh, White, Cox y Young (2011) estudiaron los predictores del abuso del móvil en una muestra de 292 jóvenes australianos entre 16 y 24 años. Encontraron que el ser más joven y la autoidentidad -entendida como la incorporación de valores, metas y componentes afectivos al autoconcepto- predecian significativamente la frecuencia de uso del teléfono móvil. Además, estas dos variables, junto con el ajuste a las normas del grupo relacional, predijeron el uso de telefonía móvil de los jóvenes. Ni la autoestima, ni la necesidad de pertenencia al grupo predijeron significativamente el comportamiento con el teléfono móvil.

\section{Diferencias en función del sexo}

Algunos estudios encuentran que las mujeres cuentan con más probabilidades de presentar un uso problemático del móvil que los varones (Takao et al., 2009), pero otros no confirman este hallazgo (Bianchi y Phillips, 2005). Los varones tienden a hacer más llamadas, pero sin indicadores de abuso, dependencia psicológica o pérdida de control (Takao et al., 2009; Bianchi y Phillips, 2005). En el estudio de Leung (2007) no se encontró relación entre el sexo y la probabilidad de pertenecer al grupo de adictos; sin embargo, tras un análisis discriminante que incorporaba las variables psicológicas, se encontró que el grupo más vulnerable lo componian mujeres con baja autoestima. Beranuy et al., (2009) encontraron que las mujeres mostraban más consecuencias negativas del uso abusivo del móvil.

En el estudio de Bianchi y Phillips (2005), las mujeres hacian un uso más social del móvil, llamaban a más personas, aunque buena parte de esas llamadas eran relacionadas con los negocios. El sexo no predijo el tiempo total de uso, ni el uso problemático, ni la cantidad de mensajes de texto enviados. Billieux et al. (2008) no encontraron diferencias entre varones y mujeres en relación al número de llamadas diarias y su duración, pero si en el número de 'sms' diarios, que era mayor en las mujeres. Las mujeres mostraron una mayor dependencia del móvil y ello se relacionaba con mayores niveles de impaciencia.
Igarashi et al. (2005) exploraron las diferencias por sexo en el uso de móviles. Utilizaron una muestra de 132 estudiantes japoneses con edades comprendidas entre los $18 \mathrm{y}$ los 23 años. Las diferencias de sexo en las estimaciones de expansión y popularidad sugieren que las mujeres son más activas que los hombres en sus redes sociales, establecidas mediante mensajes de texto, incluso en una etapa temprana, incrementando, con el tiempo, su red de contactos, que, además, tiende a ser más estable que las establecidas por los varones. El volumen de mensajes de texto enviados no fue significativamente diferente entre hombres y mujeres. Es probable que no sea el volumen, sino el contenido de los mensajes de texto, lo que permite a las mujeres mantener y ampliar sus redes.

Un estudio realizado en Suiza (Geser, 2006), sobre una muestra de 1415 sujetos, estudiantes de escuelas de oficios (entre 17 y 21 años de edad en su mayoría), exploró las diferencias por sexo en el uso del móvil. Los autores encontraron que el uso del teléfono por parte de las mujeres está más fuertemente condicionado por factores sociales exógenos. Las niñas tienen más probabilidades que los niños de haber recibido su teléfono móvil como un regalo, y su intensidad de uso está más bien determinada por variables del entorno familiar (educación parental). Además, ellas (especialmente las menores de edad) son mucho más activas en el intercambio de mensajes de texto, mientras que los varones son más frecuentemente emisores y receptores de llamadas de audio. Los varones tienden a distribuir sus Ilamadas telefónicas a través de un mayor número de amigos y a utilizar sus móviles para ampliar sus redes (poniéndose en contacto con nuevas personas con las que se busca un conocimiento más intimo). Las mujeres parecen restringir su comunicación a un número menor de amigos, con los que, sin embargo, están más frecuentemente en contacto, siendo similar el número de amigos al de familiares en el núcleo central de contactos habituales. Los resultados apoyaban la creencia generalizada de que las mujeres ven al móvil principalmente como un medio de comunicación personal subjetiva, mientras que los varones tienden a desarrollar un uso más instrumental. Sin embargo, hay un aspecto fundamental al que las mujeres dan más peso que los hombres: las cuestiones de seguridad y la utilidad del móvil para favorecerla. En último término, el estudio revela que muchas más mujeres que hombres han asimilado el teléfono móvil como un componente central de su existencia personal: por su integración en su estilo de vida o por haber desarrollado un nivel de dependencia que hace que la vida sin móvil se haya convertido en impensable.

Un estudio realizado en España (Chóliz, Villanueva y Chóliz, 2009) exploró las diferencias por sexo en el uso del móvil en una muestra de 2486 sujetos entre 12 y 18 años. Las chicas enviaban más mensajes de texto, realizaban más llamadas perdidas y dedicaban más tiempo al uso del móvil que los chicos. Por el contrario, no se obtuvieron diferencias estadisticamente significativas en el número de llamadas de voz. Respecto al gasto, y a pesar de que las mujeres contaban con menos dinero de asignación semanal que los varones, gastaban más en el móvil que ellos. Los padres también pagaban a las chicas el gasto mensual de móvil en mayor medida que 
a los varones. Estos resultados fueron en parte similares a los encontrados en otro estudio sobre 1011 estudiantes universitarios españoles (Ruiz-Olivares, Lucena, Pino y Herruzo, 2010): las mujeres envíaban más mensajes de texto y declararon más dificultades en el control del gasto que los varones; sin embargo, en este estudio las mujeres también pasaban más tiempo hablando por el móvil.

Por el contrario, Toda et al. (2006) encontraron, en un estudio ítem-a-ítem con 271 estudiantes universitarios, que los varones hacian un uso más intensivo del móvil, en todas las horas del dia y de la noche, y en cualquier situación, como durante los viajes en tren, prefiriendo las llamadas de voz. Las mujeres, en cambio, hacían un uso más limitado del aparato y preferian los mensajes de texto, sintiendo fuerte gratificación cuando recibian respuesta a los que ellas enviaban.

Grellhesl (2010) exploró las diferentes fuentes de gratificación que para varones y mujeres suponía el uso del móvil. Encontraron la accesibilidad/movilidad, la facilidad de localización de otros, relajación, escape y diversión, y coordinación para los asuntos propios. En todas ellas, las mujeres puntuaron significativamente más que los varones (si bien en el caso de la diversión sólo resultó significativo en el grupo de menor edad). La autora concluyó que el móvil resulta más importante en la mujer en la medida en que potencia su libertad para desenvolverse en el mundo en términos de mayor igualdad que lo que sus roles tradicionales le permitian.

\section{Discusión}

Tras la revisión realizada se puede concluir que el uso del móvil puede llegar a convertirse en un comportamiento disfuncional; sin embargo, la inexistencia de un consenso en la conceptualización de la adicción al móvil dificulta la delimitación del problema y su estudio. No cabe duda de que el uso abusivo del teléfono móvil presenta algunas similitudes con la adicción a sustancias, pero no está claro que ello represente realmente una adicción. Los criterios establecidos por el DSM-IV para el diagnóstico de dependencia pueden ser suficientes para clasificar una conducta como trastorno, pero son insuficientes, en el momento actual, para considerar la existencia de una adicción en el tema que nos ocupa. Sin embargo, empieza a acumularse evidencia empírica sobre el hecho de que las adicciones comportamentales comparten con la adicción a sustancias desde la historia natural, la fenomenología, la contribución genética, los mecanismos neurobiológicos y la respuesta al tratamiento (Grant, Potenza, Weinstein y Gorelick, 2010). Contamos ya con algún trabajo que encuentra que los sustratos neurocomportamentales implicados en la adicción a sustancias son esencialmente los mismos que subyacen a adicciones comportamentales, como el juego de apuestas (Ko et al., 2009) o los videojuegos (Han, Kim, Lee, Min y Renshaw, 2010). Pero tampoco hay que olvidar que esos mismos son los mecanismos que están implicados en comportamientos socialmente aceptables, como el amor romántico o apasionado (Reynaud, Karila, Blecha y Benyamina, 2010). En la medida en que el uso del móvil pasa de ser una conducta bajo el control consciente del sujeto a convertirse en un comportamiento automatizado, alejado del control superior -corteza prefrontal-, puede considerarse que cumple los requisitos para ser considerado una adicción (Everitt y Robbins, 2005).

Una importante consecuencia de esta indefinición conceptual es que cada uno de los trabajos disponibles que estudian el fenómeno del uso excesivo de teléfonos móviles, al carecer de criterios consensuados, recurre a los criterios que considera más adecuados: los propuestos para la dependencia de sustancias, los que se corresponden con la categoría de trastornos del control de los impulsos, los más concretamente aplicados al juego patológico, los tentativamente propuestos para la adicción a Internet, los derivados de la propia experiencia clínica o del conocimiento cotidiano del problema, etc. Así hemos visto que han proliferado en la última década instrumentos variados que aportan resultados rara vez replicados por grupos ajenos a su creación. Y ello cuando no se opta, como sucede en múltiples ocasiones, por diseñar un instrumento ad hoc para el estudio proyectado, sin que interesen sus propiedades psicométricas. El resultado es una inconsistencia en los resultados y una heterogénea estimación de prevalencias, que oscilan entre el $0 \%$ y el $38 \%$ en las muestras estudiadas. La calidad de los estudios (ej., muestras reclutadas, análisis psicométrico de los instrumentos) es, por otra parte, muy precaria, haciendo imposible la generalización de los resultados, que no pasan en ningún caso de ser meramente exploratorios, lo que no es óbice para que en muchos de ellos se infieran conclusiones dramáticas.

No hay que descartar la existencia de importantes condicionamientos culturales en la interpretación del tema que nos ocupa, apareciendo muchos más estudios y muchos más problemas en poblaciones asiáticas, en donde la proximidad a los centros de producción probablemente favorezca un uso más intenso. El abuso del móvil por adolescentes y jóvenes parece haber adquirido proporciones alarmantes en paises como Corea del Sur o China, lugares en los que se ha acuñado el término de "era del pulgar" ('thumb age') para describir un comportamiento intensivo, permanente, invasivo y ubicuo relacionado con el teléfono móvil, en el que los sujetos pasan mucho más tiempo del día mirando su aparato telefónico que a cualquier otro lugar del mundo (Bell, 2005; Park, 2005). En España y países afines el problema no parece haber alcanzado proporciones similares, si bien forma parte de una cultura juvenil cuyo crecimiento se produce "entre pantallas" (ordenador, televisión, cine, móvil, etc.; Gabelas Barroso, 2005), si bien el móvil parece ir desplazando paulatinamente a todas las demás.

Algo que llama la atención en los estudios revisados es el hecho de que muchas personas no tienen ningún problema en considerarse a sí mismas como "adictas al móvil". En muchos casos, la prevalencia autoatribuida supera a la estimada por los propios autores del estudio. Ésta parece ser una clara diferencia con otras adicciones, comportamentales o con sustancias: ser adicto al móvil (como sucede también con Internet) no parece ser algo denigrante y ocultable. Se diria que no se producen aquí las alteraciones neurológicas que se han propuesto como sustratos de la incapacidad para 
comprender el alcance de los problemas -low self-awarenessen los adictos a sustancias (Goldstein et al., 2009), lo que pone en cuestión bien el carácter adictivo del abuso del móvil, bien que tales alteraciones sean consustanciales a la adicción, pudiendo tratarse simplemente de la consecuencia de una adaptación a exigencias sociales (Tirapu Ustárroz, Landa y Lorea Conde, 2003) que no se dan en el caso de tecnologías socialmente aceptables.

Si el uso excesivo del móvil debe considerarse una conducta adictiva, debe también acompañarse de vulnerabilidades psicológicas, trastornos concomitantes y consecuencias negativas. La mayor parte de los estudios así lo indican. La autoestima aparece baja en casi todos los estudios, apuntando al hecho de que el uso del móvil puede liberar al sujeto con un pobre autoconcepto de arriesgarlo aún más en relaciones cara a cara. En sintonía con lo anterior, son varios los estudios que vinculan el abuso del móvil con la experimentación de síntomas depresivos, de modo que la focalización en la comunicación mediada puede operar como factor de incremento del malestar en personas vulnerables. Son de especial interés los estudios que exploran la relación con rasgos de personalidad, en la medida en que pueden informarnos de qué patrones de comportamiento pueden desarrollar, con más facilidad, adicción al móvil o sus contenidos. Varios estudios coinciden en encontrar que la extraversión, la afabilidad y el neuroticismo son los rasgos más relacionados con los patrones de uso abusivo del móvil. Sin embargo, también encuentran que la adicción presenta caracteristicas diferentes cuando predomina uno u otro. Igarashi et al. (2004) diferenciaron entre dependencia neurótica y dependencia extravertida: la primera tendría más relación con la expresión del malestar psicológico e implicaría una alta sensibilidad al contenido de los mensajes recibidos; la segunda tendría que ver con la necesidad de establecer conexión permanente con los interlocutores para buscar estimulación, con independencia de los contenidos de los mensajes. La baja afabilidad aparece más relacionada con la huida intencional del contacto interpersonal y su potencial predictivo sobre el abuso se maximiza cuando coincide con mayores niveles de neuroticismo, algo que también es habitual en las adicciones con sustancias (Terracciano, Löckenhoff, Crum, Bienvenu y Costa, 2008).

Cuando se han estudiado variables relacionadas con la socialización, los resultados son contrapuestos. Si para unos autores el móvil es un instrumento que facilita la creación y mantenimiento de redes sociales, incrementando el capital social, para otros su uso favorece el aislamiento y las sensaciones de soledad. Se requieren más estudios que pongan en relación estas variables con los rasgos estables de la personalidad, de modo que es posible que sea determinada combinación de rasgos la que utiliza el móvil en uno u otro sentido, sin que el uso excesivo de este medio sirva para otra cosa que para incrementar los problemas previos, cuando los hubiere, o bien potenciar las capacidades previas de socialización. En este sentido apuntan los trabajos que han explorado las posibles variables predictoras de adicción al móvil.

Parece existir un acuerdo en casi todos los estudios en el hecho de encontrar un patrón de uso diferente entre varo- nes y mujeres. Éstas parecen hacer un uso más interpersonal, como instrumento que favorece la intimidad en las comunicaciones, mostrando preferencia por los mensajes escritos. Los varones, en cambio, son más proclives al uso intensivo del móvil, tanto para mensajes de texto como conversaciones de voz, y para el uso de aplicaciones lúdicas. No hay estudios concluyentes sobre la probabilidad de desarrollar adicción en función del sexo, si bien las mujeres con baja autoestima parecen representar el grupo más vulnerable.

En cuanto a la caracterización del potencial adictivo asociado al uso de móvil, ha resultado ser una tarea ardua e inconsistente, debido a los cambios que han afectado a la propia fuente adictiva. Si a finales del siglo pasado se asociaba el uso del móvil a la comunicación interpersonal, todos los trabajos que se han focalizado en este aspecto han ido quedando obsoletos a medida que la telefonía móvil ha incorporado nuevos contenidos. Por ejemplo, si en un principio se estudiaban, en relación a la función de comunicación interpersonal, variables como el número de llamadas o mensajes cortos emitidos o recibidos, ello es irrelevante en el momento actual, cuando los usuarios pueden comunicarse mediante correos electrónicos que se reciben en el terminal como mensajes instantáneos, o pueden comunicarse a través de redes sociales, o utilizar chats (abiertos o restringidos a alguna de las aplicaciones), o pueden participar en directo en programas de radio y televisión, o pueden efectuar videoIlamadas, etc. Cuantificar todas las posibilidades de comunicación interpersonal actualmente disponibles exige una tecnología de la que no disponemos actualmente. Pero es que, además, otras fuentes de gratificación potencialmente adictivas han ido sumándose a la oferta disponible en el aparato móvil: juegos de estrategia o de apuestas, televisión, vídeos, música, fotografía, etc. Las investigaciones que puedan desarrollarse corren el riesgo de tornarse obsoletas en un periodo de tiempo muy breve, como ha ocurrido ya con muchas de las realizadas hasta la fecha. Se requiere un desarrollo conceptual (Garcia y Monferrer, 2009) que genere un paradigma de investigación, suficientemente amplio y flexible, del que carecemos en el momento actual.

El móvil es, en el momento actual, una plataforma para acceder a múltiples aplicaciones, y se han descrito comportamientos adictivos a muchas de ellas. En ese caso, el móvil sería un vehículo para una multiadicción (suponiendo que el usuario mostrara comportamiento adictivo a varias de esas aplicaciones simultáneamente). Sin embargo, la adicción al móvil, entendida como una adicción comportamental en sí misma, debería tener rasgos diferenciales con las otras adicciones comportamentales, ya que de otra forma no tiene sentido hablar de adicción al móvil. Dicho de otro modo, si alguien utiliza el móvil para jugar podría convertirse en adicto al juego -no al móvil-, si es adicto a Internet no quiere decir que lo sea al móvil, porque su comportamiento de navegar por la red será similar (probablemente más intenso) cuando permanezca delante de un ordenador, y así, una a una, para todas las demás aplicaciones. Al intentar delimitar qué es lo específico del móvil, el elemento clave que lo ha colocado en el ámbito de los comportamientos de riesgo adictivo es su función de comunicación interpersonal ins- 
tantánea y permanente; de hecho cuando se estudia este comportamiento como adictivo, se alude habitualmente a los 'sms' y a las Ilamadas de voz -a los que habría que añadir los más recientes 'chats' instantáneos, ya sea mediante aplicaciones tipo WhatsApp o a través de las redes sociales-. Por tanto, cabria hablar de una característica exclusiva del móvil: la inmediatez en las comunicaciones. Esta inmediatez no se cumple cuando este tipo de intercomunicación se realiza mediante ordenador, puesto que es preciso encontrarse frente a él, mientras que el móvil permite recibir el estímulo en cualquier situación y en cualquier momento. Una persona puede consultar sus correos electrónicos cuando se sienta frente al ordenador o en cualquier momento si dispone de un móvil apropiado; una persona puede buscar información de cualquier tipo a través de su ordenador cuando accede a él o utilizando su móvil en cualquier momento. En definitiva, la adicción al móvil sólo tiene sentido como objeto de estudio cuando lo que se explora es la necesidad de inmediatez en el uso de sus aplicaciones y la incapacidad para demorar la recepción del estímulo y la emisión de una respuesta.

Es posible que el actual auge de los móviles y su capacidad de penetración en la población (especialmente en los grupos más vulnerables) sean el producto de un momento concreto del desarrollo tecnológico y la dinámica de los mercados. También es posible que, como sugieren algunos autores, nos encontremos frente a la "adicción del Siglo XXI" (Ahmed, Qazi y Perji, 2011). Pero es posible, también, que se trate de una auténtica revolución en los procesos de comunicación interpersonal, para los cuales los paradigmas previos carecen de capacidad explicativa. Siguiendo la ya mencionada propuesta de Griffiths (2008), lo que lleva a considerar el uso del móvil como adictivo es un clima social que considera que los más jóvenes pasan demasiado tiempo aferrados a su móvil, y que ello debe tener consecuencias negativas para su natural proceso de crecimiento y desarrollo. De no ser por la implicación de los (cada vez) más jóvenes, difícilmente se hubiera considerado su clasificación como adicción.

En definitiva, la literatura disponible no es suficiente para afirmar la existencia de un cuadro que pueda clasificarse como adicción al móvil, si bien la evidencia acumulada aconseja seguir investigando, ante la certeza de que un determinado porcentaje de personas experimentan consecuencias negativas asociadas a un excesivo uso de este medio de comunicación. Los estudios actuales son insuficientes: cada estudio parte de diferentes marcos conceptuales, los diseños son a menudo inadecuados, existe una profusión de instrumentos de evaluación cuyas propiedades psicométricas se desconocen y los resultados no pueden ser generalizados. Los indicios más sólidos se encuentran en estudios que exploran la relación entre patrones de uso del móvil y variables psicológicas y psicopatológicas; sin embargo, la multiplicidad de marcos teóricos y variables utilizadas, así como la inexistencia de estudios de replicación, tampoco permiten extraer conclusiones sólidas. Desde la perspectiva actual, el estudio de la adicción al móvil se torna complejo. ¿Es al móvil, como plataforma de oferta múltiple de gratificaciones, o es a una o varias de esas actividades ofertadas a lo que se hace adicta una persona? En tanto que los meca- nismos neurológicos y neuropsicológicos son los mismos que pueden hacer perder el control superior sobre el comportamiento ¿son aplicables los criterios aplicados a otras conductas adictivas al uso y abuso del móvil? ¿o lo son a una o alguna de las conductas que, a través de él, pueden llegar a desarrollarse? ¿podría llegar a considerarse el abuso del móvil como una 'poliadicción' comportamental? ¿o es el móvil reforzante en sí mismo y las conductas que a través de él se desarrollan son intercambiables y puede prescindirse sin problemas de una para dedicar el tiempo a otra? Son muchas las preguntas que quedan sin responder en el momento actual y, además, es posible que estas preguntas sean insuficientes dentro de muy poco tiempo, puesto que la evolución del móvil como plataforma está lejos de haber frenado su desarrollo. En todo caso, los datos de esta revisión acentúan la necesidad de acordar unos criterios unificados que permitan delimitar los objetivos de la investigación que, de otro modo, corre el riesgo de acumular aún más estudios difícilmente comparables y de muy poca utilidad epidemiológica y clínica. La adopción de estos criterios, así como el uso de instrumentos adecuados son condiciones necesarias para posibilitar el estudio científico de un fenómeno de enormes dimensiones y unas consecuencias difícilmente explicables por el conocimiento científico actual.

\section{Referencias}

Ahmed, I., Qazi, T. F. y Perji, K. (2011). Mobile phone to youngsters: Necessity or addiction. African Journal of Business Management, 5, 12512-12519. doi: 10.5897/AJBM11.626

Ahmed, I., Ramzan, M., Qazi, T. F. y Jabeen, S. (2011). An investigation of mobile phone consumption patterns among students and professionals; is there any difference? European Journal of Economics, Finance \& Administrative Sciences, 39, 126-143.

APA (2000). Diagnostic and Statistical Manual of Mental Disorders, 4th Edition, Text Revision. Washington, DC: American Psychiatric Association.

APA (2011). DSM-5 Development. American Psychiatric Association. Recuperado de: (http://www.dsm5.org/proposedrevision/Pages/ SubstanceUseandAddictiveDisorders.aspx). Consultado el 03/03/2012.

Augner, C. y Hacker, G. W. (2011). Associations between problematic mobile phone use and psychological parameters in young adults. International Journal of Public Health, en prensa; doi: 10.1007/ s00038-011-0234-z.

Backer-Grøndahl, A. y Sagberg, F. (2011). Driving and telephoning: Relative accident risk when using hand-held and hands-free mobile phones. Safety Science, 49, 324-330. doi: 10.1016/j. ssci.2010.09.009

Bell, G. (2005). The age of the thumb: a cultural reading of mobile technologies from Asia. En P. Glotz, S. Bertschi y C. Locke (eds.), Thumb culture: the meaning of mobile phones for society (pp. 67-87). Bielefeld: Deutsche Bibliothek.

Beranuy, M., Oberst, U., Carbonell, X. y Chamarro, A. (2009). Problematic Internet and mobile phone use and clinical symptoms in college students: The role of emotional intelligence. Computers in Human Behavior, 25, 1182-1187. doi:10.1016/j.chb.2009.03.001 
Beranuy Fargues, M., Chamarro Lusar, A., Graner Jordania, C. y Carbonell Sánchez, X. (2009). Validación de dos escalas breves para evaluar la adicción a Internet y el abuso de móvil. Psicothema, 21, 480-485.

Beranuy Fargues, M., Sánchez Carbonell, X., Graner Jordania, C., Castellana Rosell, M. y Chamarro Lusar, A. (2006). Uso y abuso del teléfono móvil en jóvenes y adolescentes. Comunicación presentada al XXI Congreso Internacional de Comunicación. Pamplona, 9-10 de noviembre de 2006. Recuperado de: http:// www.unav.es/fcom/cicom/2006/es/grupostrabajo.htm.

Bianchi, A. y Phillips, J. G. (2005). Psychological predictors of problem mobile phone use. CyberPsychology \& Behavior, 8, 39-51. doi:10.1089/cpb.2005.8.39

Billieux, J., Van der Linden, M. y Rochat, L. (2008). The role of impulsivity in actual and problematic use of the mobile phone. Applied Cognitive Psychology, 22, 1195-1210. doi: 10.1002/ acp.1429

Brown, R. I. F. (1997). A theoretical model of the behavioural addictions - applied to offending. En J. E. Hodge, M. McMurran y C. R. Hollin (Eds.), Addicted to crime (pp. 13-65). Glasgow: John Wiley \& Sons Ltd.

Buchinger, S., Kriglstein, S., Brandt, S. y Hlavacs, H. (2011). A survey on user studies and technical aspects of mobile multimedia applications. Entertainment Computing, en prensa; doi:10.1016/j. entcom.2011.02.001.

Butt, S. y Phillips, J. G. (2008). Personality and self-reported mobile phone use. Computers in Human Behavior, 24, 346-360. doi: 10.1016/j.chb.2007.01.019

Caplan, S. E. (2007). Relations among loneliness, social anxiety, and problematic Internet use. CyberPsychology \& Behavior, 10, 234242. doi:10.1089/cpb.2006.9963

Carbonell, X., Guardiola, E., Beranuy, M. y Bellés, A. (2009). A bibliometric analysis of the scientific literature on Internet, video games, and cell phone addiction. Journal of the Medical Library Association, 97, 102-107. doi: 10.3163/1536-5050.97.2.006

Cassidy, S. (2006). Using social identity to explore the link between a decline in adolescent smoking and an increase in mobile phone use. Health Education, 106, 238-250. doi: 10.1108/09654280610658578

Chak, K. y Leung, L. (2004). Shyness and locus of control as predictors of Internet addiction and Internet use. CyberPsychology \& Behavior, 7, 559-570. doi:10.1089/cpb.2004.7.559

Chen, Y. F. (2006). Social phenomena of mobile phone use: An exploratory study in Taiwanese college students. Journal of Cyber Culture and Information Society, 11, 219-244.

Chen, Y. F. (2007). The mobile phone and socialization: The consequences of mobile phone use in transitions from family to school life of U.S. college students. Tesis Doctoral. University of New Jersey. Recuperado de: http://mss3.libraries.rutgers.edu/ dlr/outputds.php?pid= rutgers-lib:21776\&mime=application $/$ pdf\&ds=PDF-1

Chóliz, M. (2010). Mobile phone addiction: a point of issue. Addiction, 105, 373-374. doi: 10.1111/j.1360-0443.2009.02854.x

Chóliz, M. y Villanueva, V. (2009). Questionnaire of Dependence of Mobile Phone: psychometric properties and gender differences. 11th European Congress of Psychology. Oslo, 7-10 de julio de 2009.
Chóliz, M., Villanueva, V. y Chóliz, M. C. (2009). Ellas, ellos y su móvil: Uso, abuso (¿y dependencia?) del teléfono móvil en la adolescencia. Revista Española de Drogodependencias, 34, 74-88.

Chóliz Montañés, M. y Villanueva Silvestre, V. (2011). Evaluación de la adicción al móvil en la Adolescencia. Revista Española de Drogodependencias, 36, 165-184.

Davie, R., Panting, C. y Charlton, T. (2004). Mobile phone ownership and usage among pre-adolescents. Telematics and Informatics, 21, 359-373. doi: 10.1016/j.tele.2004.04.001

de Gracia, M., Vigo, M., Fernández Pérez, M.J., y Marco, M. (2002). Problemas conductuales relacionados con el uso de Internet: un estudio exploratorio. Anales de Psicología, 18, 273-292.

Ehrenberg, A., Juckes, S., White, K. M., \& Walsh, S. P. (2008). Personality and self-esteem as predictors of young people's technology use. CyberPsychology \& Behavior, 11, 739-741. doi:10.1089/ cpb.2008.0030

Everitt, B. J. y Robbins, T. W. (2005). Neural systems of reinforcement for drug addiction: from actions to habits to compulsion. Nature Neuroscience, 8, 1481-1489. doi:10.1038/nn1579

Gabelas Barroso, J. A. (2005). Crecer entre pantallas. En Libro de Ponencias del Congreso: ser adolescente hoy (pp. 273-283). Madrid: Fundación de Ayuda contra la Drogadicción.

García, M. C. y Monferrer, J. (2009). Propuesta de análisis teórico sobre el uso del teléfono móvil en adolescentes. Comunicar, 17, 83-92. doi: 10.3916/c33-2009-02-008

Geser, H. (2006). Are girls (even) more addicted? Some gender patterns of cell phone usage. En: Sociology in Switzerland: Sociology of the Mobile phone. Zurich: Online Publications. Recuperado de: http:// socio.ch/mobile/t_geser3.pdf.

Goldstein, R. Z., Craig, A. D., Bechara, A., Garavan, H., Childress, A. R., Paulus, M. P. y Volkow, N. D. (2009). The neurocircuitry of impaired insight in drug addiction. Trends of Cognitive Science, 13, 372380. 10.1016/j.tics.2009.06.004

Grant, J. E., Potenza, M. N., Weinstein, A. y Gorelick, D. A. (2010). Introduction to Behavioral Addictions. American Journal of Drug and Alcohol Abuse, 36, 233-241.

Grellhesl, M. (2010). Using the uses and gratifications theory to understand gratifications sought through text messaging practices of male and female undergraduate students. Tesis Doctoral. Texas Tech University. Recuperado de: http://dspace.lib. ttu.edu/etd/handle/2346/ETD-TTU-2010-05-555.

Griffiths, M. D. (2008). The biopsychosocial and "complex" systems approach as a unified framework for addiction. Behavioral and Brain Sciences, 31, 446-447. doi: 10.1017/S0140525X08004822

Ha, J. H., Chin, B., Park, D. H., Ryu, S. H. y Yu, J. (2008). Characteristics of excessive cellular phone use in Korean adolescents. CyberPsychology \& Behavior, 11, 783-784. doi:10.1089/ cpb.2008.0096

Halayem, S., Nouira, O., Bourgou, S., Bouden, A., Othman, S. y Halayem, M. (2010). Le téléphone portable : une nouvelle addiction chez les adolescents. La Tunisie Medicale, 88, 593- 596.

Han, D. H., Kim, Y. S., Lee, Y. S., Min, K. J. y Renshaw, P. F. (2010). Changes in cue-induced, prefrontal cortex activity with videogame play. CyberPsychology, Behavior, and Social Networking, 13, 655-661. doi:10.1089/cyber.2009.0327

Hashem, M. E. (2009). Impact and implications of new information technology on Middle Eastern youth. Global Media Journal, 8(14), 1. Recuperado de: http://lass.calumet.purdue.edu/cca/gmj/sp09/ gmj-sp09-hashem.htm. 
Hartmann, M., Rössler, P. y Höflich, J. R. (2008). After the mobile phone?: social changes and the development of mobile communication. Berlin: Frank \& Timme.

Heinrich, S., Thomas, S., Heumann, C., von Kries, R. y Radon, K. (2011). The impact of exposure to radio frequency electromagnetic fields on chronic well-being in young people. A cross-sectional study based on personal dosimetry. Environment International, 37, 26-30. doi: 10.1016/j.envint.2010.06.008

Hooper, V. y Zhou, Y. (2007). Addictive, dependent, compulsive? A study of mobile phone usage. 20th Bled eConference eMergence: Merging and Emerging Technologies, Processes, and Institutions. Junio 4-6; Bled: Slovenia. Recuperado de: http://ecom.fov.uni-mb. si/proceedings.nsf/0/637808f705bd12d2c12572ee007a38f8/\$FI LE/22_Hooper.pdf.

Igarashi, T., Motoyoshi, T., Takai, J. y Yoshida, T. (2004). No mobile, no life: Self-perception and text-message dependency among Japanese high school students. Computers in Human Behavior, 24, 2311-2324. doi: 10.1016/j.chb.2007.12.001

Igarashi, T., Takai, J. y Yoshida, T. (2005). Gender differences in social network development via mobile phone text messages: A longitudinal study. Journal of Social and Personal Relationships, 22, 691-713. doi: 10.1177/0265407505056492

Instituto de Adicciones (2008). Estudio de uso problemático de las tecnologías de la información, la comunicación y el juego entre los adolescentes y jóvenes de la ciudad de Madrid. Madrid: Madrid Salud.

Ishii, K. (2004). Internet use via mobile phone in Japan. Telecommunications Policy, 28, 43-58. doi: 10.1016/j. telpol.2003.07.001

Jenaro, C., Flores, N., Gomez-Vela, M., Gonzalez-Gil, F. y Caballo, C. (2007). Problematic Internet and cell-phone use: Psychological, behavioral, and health correlates. Addiction Research \& Iheory, 15, 309-320. doi:10.1080/16066350701350247

Kamibeppu, K. y Sugiura, H. (2005). Impact of the mobile phone on junior high school students' friendships in the Tokyo metropolitan area. CyberPsychology and Behavior, 8, 121-130. doi:10.1089/ cpb.2005.8.121

Ko CH, Liu GC, Hsiao S, Yen JY, Yang MJ, Lin WC, ... Cheng, C. S. (2009). Brain activities associated with gaming urge of online gaming addiction. Journal of Psychiatry Research, 43, 739-747. 10.1016/j. jpsychires.2008.09.012

Koo, H. Y. (2009). Development of a Cell Phone Addiction Scale for Korean adolescents. Journal of Korean Academy of Nursing, 39, 818-828. doi: 10.4040/jkan.2009.39.6.818

Koo, H. Y. (2010). Cell phone addiction in highschool students and its predictors. Journal of Korean Academy of Child Health Nursing, 16, 203-210. doi: 10.4094/jkachn.2010.16.3.203

Labrador Encinas, F. J. y Villadangos González, S. M. (2010). Menores y nuevas tecnologias: conductas indicadoras de posible problema de adicción. Psicothema, 22, 180-188.

LaRue, E. M., Mitchell, A. M., Terhorst, L. y Karimi, H. A. (2010). Assessing mobile phone communication utility preferences in a social support network. Telematics and Informatics, 27, 363-369. doi: 10.1016/j.tele.2010.03.002

Lee, K. C. y Perry, S. D. (2004). Student instant message use in a ubiquitous computing environment: Effects of deficient selfregulation. Journal of Broadcasting \& Electronic Media, 48, 399420. doi: 10.1207/s15506878jobem4803_4
Leung, L. (2007). Leisure boredom, sensation seeking, self-esteem, addiction symptoms and patterns of cell phone use. En E. A. Konijn, M. A. Tanis, S. Utz y A. Linden (eds.), Mediated interpersonal communication (pp. 359-381). Mahwah, NJ: Lawrence Erlbaum Associates.

Leung, L. (2008). Linking psychological attributes to addiction and improper use of the mobile phone among adolescents in Hong Kong. Journal of Children and Media, 2, 93-113. doi: $10.1080 / 17482790802078565$

Ling, R. (2004). The mobile connection: The cell phone's impact on society. San Francisco: Morgan Kaufman.

Lu, X., Watanabe, J., Liu, O., Uji, M., Shono, M. y Kitamura, T. (2011). Internet and mobile phone text-messaging dependency: Factor structure and correlation with dysphoric mood among Japanese adults. Computers in Human Behavior, 27, 1702-1709. doi: 10.1016/j.chb.2011.02.009

Martinotti, G., Villella, C., Di Thiene, D., Di Nicola, M., Bria, P., Conte, G., ... La Torre, G. (2011). Problematic mobile phone use in adolescence: a cross-sectional study. Journal of Public Health, 19, 545-551. doi: 10.1007/s10389-011-0422-6.

Merlo, L. J. y Stone, A. M. (2007). Comorbidity of anxiety symptoms and cellular phone addiction. Anxiety Disorders Association of America 28th Annual Meeting: Poster 55. March 6-9, 2007.

Park, W. K. (2005). Mobile phone addiction. En R. Ling y P. E. Pedersen (Eds.), Mobile communications: re-negotiation of the social sphere (pp. 253-270). Londres: Springer-Verlag.

Park, N., Hwang, Y. y Huh, E. (2010). Exploring problematic mobile phone use: relationships between adolescents' characteristics and mobile phone addiction. Trabajo presentado en el Annual Meeting of the International Communication Association, Suntec Singapore International Convention \& Exhibition Centre, Suntec City, 21-06-2010. Recuperado de: http://www.allacademic.com/ meta/p404199_index.html.

Perry, S. D. y Lee, K. C. (2007). Mobile phone text messaging overuse among developing world university students. Communicatio, 33, 63-79. doi: 10.1080/02500160701685417

Phillips, J. G., Butt, S. y Blaszczynski, A. (2006). Personality and selfreported use of mobile phones for games. CyberPsychology \& Behavior, 9, 753-758. doi:10.1089/cpb.2006.9.753

Prezza, M., Pacilli, M. G. y Dinelli, S. (2004). Loneliness and new technologies in a group of Roman adolescents. Computers in Human Behavior, 20, 691-709. doi: 10.1016/j.chb.2003.10.008

PROTÉGELES (2005). Seguridad infantil y costumbres de los menores en la telefonía móvil. Estudio realizado para el Defensor del Menor. Recuperado de: http://www.protegeles.com/es_estudios2. asp.

Reynaud, M., Karila, L., Blecha, L. y Benyamina, A. (2010). Is love passion an addictive disorder? American Journal of Drug \& Alcohol Abuse, 36, 261-267. doi:10.3109/00952990.2010.495183

Ruiz-Olivares, R., Lucena, V., Pino, M. J. y Herruzo, J. (2010). Análisis de comportamientos relacionados con el uso/abuso de Internet, teléfono móvil, compras y juego en estudiantes universitarios. Adicciones, 22, 301-309.

Rutland, J. B., Sheets, T. y Young, T. (2007). Development of a scale to measure problem use of short message service: The SMS Problem Use Diagnostic Questionnaire. CyberPsychology \& Behavior, 10, 841-844. doi:10.1089/cpb.2007.9943 
Sanchez-Carbonell, X., Beranuy, M., Castellana, M., Chamarro, A. y Oberst, U. (2008). La adicción a Internet y al móvil: ¿moda o trastorno? Adicciones, 20, 149-159.

Sánchez-Martinez, M. y Otero, A. (2009). Factors associated with cell phone use in adolescents in the Community of Madrid (Spain). CyberPsychology \& Behavior, 12, 131-137. doi:10.1089/ cpb.2008.0164

Sharp, M. J. y Getz, J. G. (1996). Substance use as impression management. Personality and Social Psychology Bulletin, 22, 60-67. doi: 10.1177/0146167296221006

Söderqvist, F., Hardell, L., Carlberg, M. y Hansson, K. (2007). Ownership and use of wireless telephones: a population-based study of Swedish children aged 7-14 years. BMC Public Health, 7, 105. Recuperado de: http://www.biomedcentral.com/content/ pdf/1471-2458-7-105.pdf. doi:10.1186/1471-2458-7-105

Takao, M., Takahashi, S. y Kitamura, M. (2009). Addictive personality and problematic mobile phone use. CyberPsychology \& Behavior, 12, 501-507. doi:10.1089/cpb.2009.0022

Terracciano, A., Löckenhoff, C. E., Crum, R. M., Bienvenu, O. J. y Costa, P. T. Jr. (2008). Five-Factor Model personality profiles of drug users. BMC Psychiatry, 8, 22. recuperado de: http://www.biomedcentral. com/content/pdf/1471-244X-8-22.pdf. doi: 10.1186/1471-244X8-22

Thomée, S., Eklöf, M., Gustafsson, E., Nilsson, R. y Hagberg, M. (2007). Prevalence of perceived stress, symptoms of depression and sleep disturbances in relation to information and communication technology (ICT) use among young adults. An explorative prospective study. Computers in Human Behavior, 23, 1300-1321. 10.1016/j.chb.2004.12.007

Thomée, S., Härenstam, A. y Hagberg, M. (2011). Mobile phone use and stress, sleep disturbances, and symptoms of depression among young adults - a prospective cohort study. BMC Public Health, 11, 66. Recuperado de: http://www.biomedcentral.com/14712458/11/66. doi:10.1186/1471-2458-11-66

Tirapu Ustárroz, J., Landa, N. y Lorea Conde, I. (2003). Sobre las recaídas, la mentira y la falta de voluntad de los adictos. Adicciones, 15, 7-16.

Toda, M., Monden, K., Kubo, K. y Morimoto, K. (2004). Cellular phone dependence tendency of female university students. Japanese Journal of Hygiene, 59, 383-386.
Toda, M., Monden, K., Kubo, K. y Morimoto, K. (2006). Mobile phone dependence and health-related lifestyle of university students. Social Behavior and Personality, 34, 1277-1284. doi: 10.2224/ sbp.2006.34.10.1277

Turan, N., Polat, O., Karapirli, M., Uysal, C. y Turan, S. G. (2011). The new violence type of the era: Cyber bullying among university students: Violence among university students. Neurology, Psychiatry and Brain Research, 17, 21-26. doi: 10.1016/j. npbr.2011.02.005

Van der Linden, M., d'Acremont, M., Zermatten, A., Jermann, F., Laroi, F., Willems, S., ... Bechara. A. (2006). A French adaptation of the UPPS Impulsive Behavior Scale: Confirmatory factor analysis in a sample of undergraduates. European Journal of Psychological Assessment, 22, 38-42. doi : 10.1027/1015-5759.22.1.38

Viñas, F. y González, M. (2010). Amenazas a través de la telefonía móvil e internet: perfil psicológico y consecuencias emocionales. Acción Psicológica, 7, 31-40.

Walsh, S. P., White, K. M. y Young, R. M. (2007) Young and connected: Psychological influences of mobile phone use amongst Australian youth. En Goggin, G. y Hjorth, L. (Eds.), Proceedings Mobile Media 2007 (pp. 125-134). Sydney: University of Sydney.

Walsh, S. P., White, K. M. y Young, R. M. (2008). Over-connected? A qualitative exploration of the relationship between Australian youth and their mobile phones. Journal of Adolescence, 31, 77-92. doi: 10.1016/j.adolescence.2007.04.004

Walsh, S. P., White, K. M. y Young, R. M. (2010). Needing to connect: The impact of self and others on young people's involvement with their mobile phone. Australian Journal of Psychology, 62, 194203. doi: $10.1080 / 00049530903567229$

Walsh, S. P., White, K. M., Cox, S. y Young, R. McD. (2011). Keeping in constant touch: The predictors of young Australians' mobile phone involvement. Computers in Human Behavior 27, 333-342. doi: 10.1016/j.chb.2010.08.011

Young, K. S. (1996). Caught in the Net: how to recognize the signs of Internet addiction and a winning strategy for recovery. New York: John Wiley \& Sons.

Zulkefly, S. N. y Baharudin, R. (2009). Mobile Phone use Amongst Students in a University in Malaysia: Its Correlates and Relationship to Psychological Health. European Journal of Scientific Research, 37, 206-218. 